\title{
PENGEMBANGAN GAME MARINE ECOSYSTEM HERO MENGGUNAKAN FUZZY LOGIC
}

\author{
Mungki Astiningrum ${ }^{1}$, Dian Hanifudin Subhi ${ }^{2}$, Dhike Almira Ramadiyah ${ }^{3}$ \\ 1,2,3 Program Studi Teknik Informatika, Jurusan Teknologi Informasi, Politeknik Negeri Malang \\ ${ }^{1}$ mungki.polinema@gmail.com, ${ }^{2}$ dhanifudin@gmail.com, ${ }^{3}$ dhikealmiraa@gmail.com
}

\begin{abstract}
Abstrak
Game merupakan hiburan yang biasanya diangkat dari masalah dalam kehidupan sehari-hari, salah satunya adalah masalah ekosistem laut. Pada saat ini kebanyakan kondisi ekosistem laut sangat memprihatinkan dikarenakan kurangnya kepedulian masyarakat akan kebersihan ekosistem laut. Untuk menyampaikan pesan agar masyarakat peduli pada lingkungan laut diperlukan media yang interaktif, maka dari itu dibuat sebuah Game yang bernamakan Marine Ecosystem Hero. Game ini memberikan misi agar player dapat mengumpulkan sampah sebanyak mungkin untuk mendapatkan poin sebelum waktu habis. Poin dan sisa waktu digunakan untuk menghitung total skor. Oleh karena itu, dibutuhkan sebuah metode yaitu Fuzzy Logic untuk menghitung skor akhir player sehingga dapat ditentukan apakah player dapat lolos ke level selanjutnya atau tidak.

Hasil dari penelitian ini menunjukkan bahwa implementasi metode Fuzzy Logic berjalan dengan baik dalam Game Marine Ecosystem Hero. Game ini dinilai untuk memberikan nilai score yang sesuai pada setiap levelnya. Sesuai hasil dari 30 responden game ini memenuhi kepuasan user sebanyak $63 \%$.
\end{abstract}

Kata kunci : Game, Ekosistem Laut, Marine Ecosystem Hero, Fuzzy Logic.

\section{Pendahuluan}

Indonesia mempunyai keanekaragaman hayati yang tinggi. Keanekaragaman tersebut tidak terlepas dari ekosistem. Dimana ekosistem didefinisikan sebagai suatu unit ekologi di mana komunitas organisme dan lingkungan fisiknya saling berinteraksi secara timbal balik (Likens, 1992) Supratna, J. (2008). Sebagai masyarakat umum kebersihan dan kelestariannya harus kita jaga. Ekosistem yang mempunyai kekayaan yang tinggi adalah ekosistem laut. Hal yang paling sering terjadi adalah terlalu banyaknya sampah plastik yang dibuang sembarangan sehingga membuat ekosistem laut kotor dan dapat membahayakan ikan-ikan dan terumbu karang. Padahal terumbu karang merupakan penunjang kehidupan dari makhluk hidup di bawah laut. Sehingga masih banyak masyarakat yang belum memahami tentang kebersihan dan kelestarian ekosistem laut.

Dari permasalahan tersebut, perlu dibuat sebuah game untuk membantu masyarakat khususnya pada generasi muda saat ini agar paham dan peduli dengan lingkungan ekosistem laut. Game yang akan dibuat adalah Game Marine ecosystem hero dimana game tersebut player atau akan diberikan misi untuk membersihkan sampah-sampah plastic.

Game ini akan diberikan kecerdasan buatan yaitu Fuzzy logic. Fuzzy logic akan digunakan untuk menentukan apakah player berhak lolos ke level selanjutnya atau tidak. Fuzzy logic digunakan karena dapat merepresentasikan unsur ketidakpastian diantara dua hal tersebut, sehingga dapat memberikan keputusan yang adil dan lebih manusiawi.

Berdasarkan latar belakang yang telah dijelaskan diatas, maka didapatkan rumusan masalah yang pertama yaitu tentang bagaimana memberikan pengetahuan seputar kebersihan dan pelestarian ekosistem laut melalui sebuah game. Yang kedua, bagaimana mengimplementasikan fuzzy logic dalam game penyelamatan ekosistem laut.

Tujuan pembuatan game ini adalah membuat game edukasi penyelamatan ekosistem laut dengan misi membersihkan sampah plastik. Selain itu membuat game penyelamatan ekosistem laut menggunakan metode fuzzy logic sebagai kecerdasan buatan sehingga dapat memberikan keputusan yang tepat dalam game tersebut.

Batasan-batasan masalah yang diambil yaitu game ini berbasis android, berformat 2D dan dirancang untuk single player. Game ini terdiri dari 3 level, mengambil setting ekosistem laut di Indonesia dan pengetahuan yang ingin disampaikan melalui game ini adalah pentingnya kesadaran dan kepedulian masyarakat akan kebersihan ekosistem laut.

\section{Landasan Teori}

\subsection{Game}

Game berasal dari kata bahasa inggris yang memiliki arti dasar Permainan. Definisi permainan sendiri adalah jenis kegiatan bermain yang dilakukan dalam konteks berpura-pura dari 
kenyataan. Game juga bisa diartikan sebagai arena keputusan dan aksi pemainnya. Ada target-target yang ingin dicapai pemainnya. Kelincahan intelektual, pada tingkat tertentu, merupakan ukuran sejauh mana game itu menarik untuk dimainkan secara maksimal Wolf, M. J.P. (2012).

\subsection{Fuzzy Logic}

Fuzzy logic adalah sebuah metodologi berhitung dengan variabel kata-kata (linguistic variable) sebagai pengganti berhitung dengan bilangan. Kata-kata digunakan dalam fuzzy logic memang tidak sepresisi bilangan, namun kata-kata jauh lebih dekat dengan intuisi manusia Naba, A. (2009).

\subsubsection{Fuzzy Sugeno}

Fuzzy Sugeno merupakan metode infrerensi fuzzy untuk aturan yang direpresentasikan dalam bentuk IF-THEN, dimana output (konsekuen) sistem tidak berupa himpunan fuzzy, melainkan berupa konstanta atau persamaan linear. Metode ini diperkenalkan oleh Takagi-Sugeno Kang pada tahun 1985. Model Sugeno menggunakan fungsi keanggotaan Singleton yaitu fungsi keanggotaan yang memiliki derajat keanggotan 1 pada suatu nilai crisp tunggal dan 0 nilai crisp yang lain.

Pada proses fuzzy inference system (FIS) dapat dibagi dalam lima bagian, yaitu fuzzifikasi input, operasi fuzzy logic, implikasi, agregasi dan deffuzyfikasi.

Fuzzy Model Sugeno merupakan varian dari model Mamdani dan memiliki bentuk aturan seperti : IF $\mathrm{x} 1$ is $\mathrm{A} 1$ AND.. $\mathrm{xn}$ is An THEN $\mathrm{y}=\mathrm{f}(\mathrm{x} 1, \mathrm{x} 2$.. $\mathrm{xn})$

Dimana $\mathrm{x}$ merupakan parameter input, $\mathrm{A}$ merupakan nilai dari parameter, $f$ merupakan sembarang fungsi dari variabel-variabel masukan yang nilainya berada dalam interval variabel keluaran. Proses defuzzyfikasi pada metode Sugeno menghitung center of single-ton:

$Z^{*}=\frac{z_{\mu c}(z) s}{z_{\mu_{L}}(z)}$

Keterangan :

$\mathrm{Z}^{*}=$ Hasil deffuzyfikasi

$\Sigma \mu c(\bar{Z})=$ hasil minimum atau $\alpha$-predikat

$\overline{\boldsymbol{z}}=$ hasil agregasi

\section{Metodologi penelitian}

Dalam pengembangan game Marine
ecosystem hero menggunakan metode pengembangan Multimedia Development Life Cycle $(M D L C)$. Pengembangan metode multimedia ini dilakukan berdasarkan enam tahap, yaitu konsep, desain, pengumpulan materi, pembuatan, testing dan distribusi.

\section{Analisis dan Perancangan}

\subsection{Perancangan Karakter}

Pembuatan karakter game ini menggunakan software Adobe Illustrator. Karakter utama atau player adalah seorang penyelam, selain itu juga terdapat NPC berupa ikan-ikan sebagai enemy dari player. Dan terdapat sampah-sampah plastik yang harus dikumpulkan oleh player.

Tabel 1 Karakter dan objek sampah

\begin{tabular}{|c|c|c|}
\hline No. & Karakter/Objek & Keterangan \\
\hline 1. & Player & $\begin{array}{l}\text { Player merupakan seorang } \\
\text { penyelam yang bertugas } \\
\text { mengumpulkan sampah- } \\
\text { sampah plastik. }\end{array}$ \\
\hline 2. & 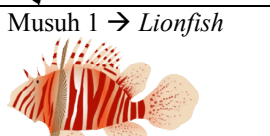 & $\begin{array}{l}\text { Terdapat pada level } 1,2 \\
\text { dan } 3 \text { yang dapat } \\
\text { mengurangi nyawa player } \\
\text { sebanyak } 10 \% \text {. }\end{array}$ \\
\hline 3. & $\begin{array}{l}\text { Musuh } 2 \rightarrow \\
\text { Surgeonfish }\end{array}$ & $\begin{array}{l}\text { Terdapat pada level } 1,2 \\
\text { dan } 3 \text { yang dapat } \\
\text { mengurangi nyawa player } \\
\text { sebanyak } 10 \% \text {. }\end{array}$ \\
\hline 4. & $\begin{array}{l}\text { Musuh } 3 \rightarrow \text { Portuguese } \\
\text { man o' war }\end{array}$ & $\begin{array}{l}\text { Terdapat pada level } 2 \text { dan } \\
3 \text { yang dapat mengurangi } \\
\text { nyawa player sebanyak } \\
25 \% \text {. }\end{array}$ \\
\hline 5. & $\begin{array}{l}\text { Musuh } \rightarrow \text { Blue ringed } \\
\text { octopus }\end{array}$ & $\begin{array}{l}\text { Terdapat pada level } 3 \text { yang } \\
\text { dapat mengurangi nyawa } \\
\text { player sebanyak } 35 \% \text {. }\end{array}$ \\
\hline 6. & $\begin{array}{l}\text { Sampah Bungkus } \\
\text { Plastik }\end{array}$ & $\begin{array}{l}\text { Bungkus plastik } \\
\text { mempunyai poin sebanyak } \\
10 \text { poin. }\end{array}$ \\
\hline 7. & Sampah Kresek & $\begin{array}{l}\text { Kresek mempunyai poin } \\
\text { sebanyak } 15 \text { poin. }\end{array}$ \\
\hline 8. & Sampah Bungkus Snack & $\begin{array}{l}\text { Bungkus snack mempunyai } \\
\text { poin sebanyak } 20 \text { poin. }\end{array}$ \\
\hline 9. & Sampah Botol & $\begin{array}{l}\text { Botol mempunyai poin } \\
\text { sebanyak } 25 \text { poin. }\end{array}$ \\
\hline
\end{tabular}




\subsection{Perancangan Kecerdasan Buatan}

Kecerdasan buatan menggunakan metode fuzzy sugeno yang digunakan untuk menentukan apakah player berhak lolos ke level selanjutnya atau tidak. Variabel-variabel yang digunakan untuk menentukan kenaikan level adalah Point yang merupakan nilai yang dikumpulkan player dari objek sampah-sampah plastik dan variabel Time yang merupakan sisa waktu yang telah digunakan oleh player. Dalam proses Fuzzy Inference System terdapat 6 tahapan, yaitu:

\section{1) Fuzzyfikasi}

Menentukan derajat keanggotaan variabel time dan point.

- Variabel Time

Berikut ini adalah fungsi keanggotaannya :

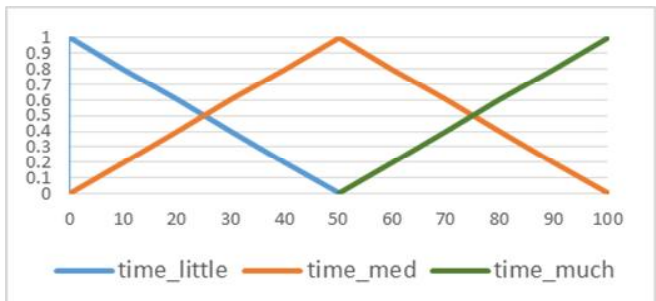

Gambar 1. Fungsi keanggotaan time

- Variabel Point

Berikut adalah fungsi keanggotaan point :

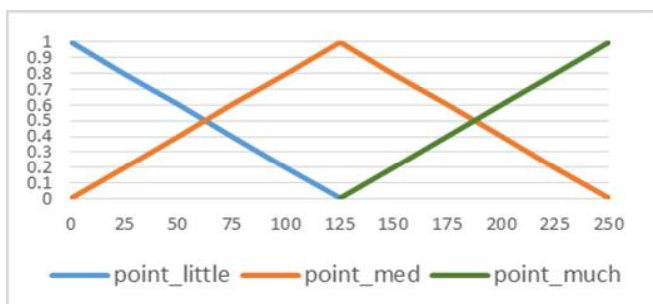

Gambar 2. Fungsi keanggotaan point level

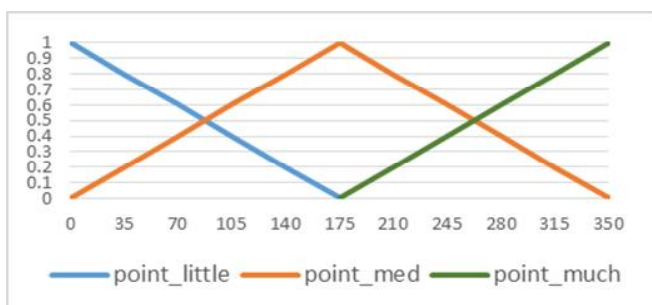

Gambar 3. Fungsi keanggotaan point level 2

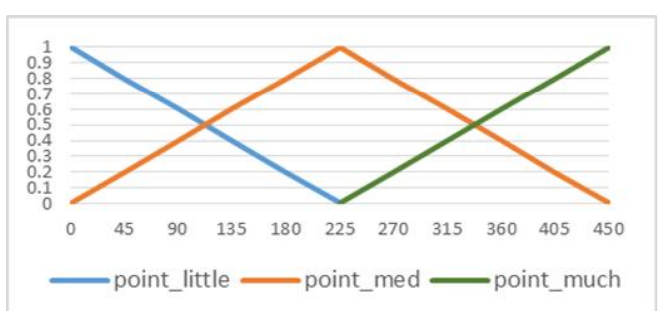

Gambar 4. Fungsi keanggotaan point level 3
2) Operasi Logika fuzzy

Setelah diperoleh derajat keanggotaan dari variabel, maka dapat diketahui variabel time dan point masuk dalam kategori yang mana. Setelah ditentukan kategorinya, selanjutnya dicocokkan dengan rule-rule yang dibuat. Setelah itu ditentukan nilai minimal dari masing-masing rule. Dari 2 variabel time dan point dapat ditentukan 9 rule, yaitu:

- IF time_little AND point_little THEN score_bad

- IF time_little AND point_med THEN score_bad

- IF time_little AND point_much THEN score_good

- IF time_med AND point_little THEN score_bad

- IF time_med AND point_med THEN score_good

- IF time_med AND point_much THEN score_excellent

- IF time_much AND point_little THEN score_bad

- IF time_much AND point_med THEN score excellent

- IF time_much AND point_much THEN score excellent

3) Implikasi

Nilai keluaran dari IF-THEN rule dapat diambil nilai minimum yang berasal dari masingmasing variabel time dan point yang ada dalam rule yang sudah dicocokkan. Hasil minimum dari kedua variabel tersebut dinamakan $\alpha$-predikat.

4) Agregasi

Menentukan variabel keluaran yang ada dalam rule-rule yang telah dicocokkan. Variabel keluaran dari IF-THEN rule tersebut adalah variabel score. Dari rule-rule yang sudah dicocokkan tadi maka akan memperoleh angka baru dari variabel score, berikut adalah kurva dan derajat keanggotaan dari variabel score.

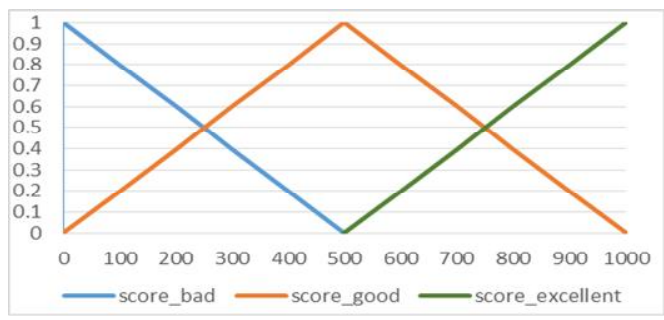

Gambar 5. Kurva variabel score

5) Defuzzyfikasi

Menghitung score akhir yang berasal dari point dan time. Untuk level 1 score harus lebih dari 500, untuk level 2 score harus lebih dari 550 , sedangkan untuk level 3 score harus lebih dari 600 .

\subsection{Perancangan Algoritma Level}

- Level 1

Pada level 1, point player akan selalu nol dan health player selalu $100 \%$. Player mempunyai misi mengambil sampah-sampah plastik. Jenis sampah 
yang harus diambil yaitu plastik yang mempunyai poin sebanyak 10 poin, kresek 15 poin, bungkus snack 20 poin, botol 25 poin. Dalam menjalankan misi terdapat musuh-musuh yang akan mengganggu player. Jika player mengenai musuh maka health player akan berkurang. Musuh-musuh yang terdapat pada level 1 yaitu Lionfish dan Surgeonfish yang masing-masing dapat mengurangi health bar sebanyak $10 \%$.

Permainan akan game over apabila waktu habis atau healthbar samadengan $0 \%$. Jika player tidak dalam kedua kondisi tersebut, player dapat melanjutkan mengambil sampah plastik, yang nantinya akan ada sebuah garis finish untuk mengakhiri level. Setelah mencapai garis finish barulah dihitung score total. Jika total score lebih dari 500 maka dapat lolos ke level 2.

- Level 2 dan 3

Perancangan algoritma level 2 dan 3 hampir sama dengan level 1 namun bertambah satu musuh lagi yaitu Portuguese man o' war (ubur-ubur) yang dapat mengurangi health bar sebanyak $25 \%$. Total score yang harus dicapai adalah minimal 550. Sedangkan pada level 3 bertambah satu musuh lagi yaitu Blue ringed octopus yang dapat mengurangi health bar sebanyak $35 \%$. Total score yang harus dicapai adalah minimal 600. Jika total score lebih dari 600 maka player telah menyelesaikan permainan dan akan menjumpai epilog setelahnya.

\section{Implementasi}

\subsection{Implementasi Pembuatan Game}

Implementasi Game Marine ecosystem hero ini menggunakan 2 perangkat lunak utama yaitu UnityGame Engine versi 5.4.2 dan Adobe Illustrator $\mathrm{CC}$ yang digunakan utuk membuat sprite dalam game.

\subsection{Implementasi Metode}

Metode Fuzzy Sugeno pada game Marine ecosystem hero menggunakan dua variabel yaitu variabel time dan points. Variabel-variabel tersebut digunakan untuk mendapatkan sebuah nilai baru yaitu score, dimana score tersebut dapat menentukan apakah player berhak lolos ke level selanjutnya atau tidak. Pada gambar 6 merupakan tampilan untuk score yang melebihi batas minimal sehingga dapat lolos ke level selanjutnya. Pada gambar 7 merupakan tampilan untuk score yang tidak melebihi batas minimal, sehingga player dinyatakan gagal dalam melakukan misi.

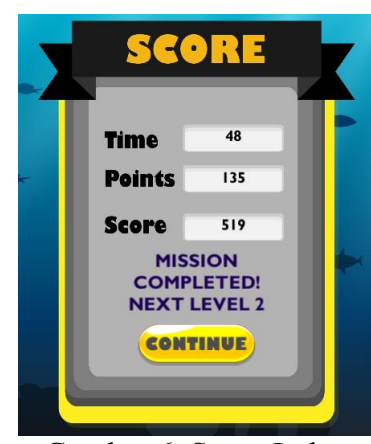

Gambar 6. Score Lolos

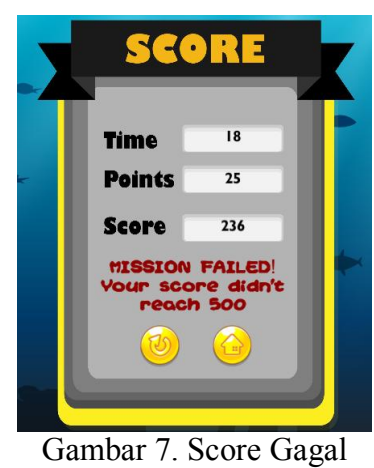

\section{Pengujian dan Pembahasan}

\subsection{Pengujian Alpha dan Betha}

Pengujian alpha dilakukan secara black box dengan hanya memperhatikan masukan ke dalam sistem dan keluaran dari masukan tersebut. Hasil pengujian alpha berjalan dengan baik sesuai dengan hasil yang diharapkan. Untuk pengujian betha dilakukan dengan menggunakan kuesioner yang diisi oleh user setelah bermain game. Dalam kuesioner menu user diminta untuk menilai tentang user interface dan fungsi button. Dalam kuesioner prolog dan epilog user diminta untuk menilai cerita yang disampaikan dan serta feedback yang diterima oleh user. Dalam kuesioner karakter game user diminta untuk menilai desain dan animasi dari karakter. Dalam kuesioner game, user diminta untuk menilai bagaimana tahapan, kesulitan, kemenarikan game itu sendiri dan kesuaian score terhadap game.

Tabel 2. Hasil kuesioner menu

\begin{tabular}{|l|l|l|}
\hline & $\# 1$ & $\# 2$ \\
\hline Rata-rata & 4.77 & 4.03 \\
\hline Rata-rata total & 4,4 & \\
\hline
\end{tabular}

Tabel 3. Hasil kuesioner prolog dan epilog

\begin{tabular}{|l|l|l|}
\hline & $\# 3$ & $\# 4$ \\
\hline Rata-rata & 3,73 & 3,67 \\
\hline Rata-rata total & 3,7 & \\
\hline
\end{tabular}

Tabel 4. Hasil kuesioner karakter game

\begin{tabular}{|l|l|l|l|}
\hline & $\# 5$ & $\# 6$ & $\# 7$ \\
\hline Rata-rata & 4,6 & 4,73 & 4,167 \\
\hline Rata-rata total & 4,5 & \multicolumn{3}{|l}{} \\
\hline
\end{tabular}


Tabel 5. Hasil kuesioner game

\begin{tabular}{|l|l|l|l|l|}
\hline & $\# 8$ & $\# 9$ & $\# 10$ & $\# 11$ \\
\hline Rata-rata & 4,03 & 4,1 & 4,367 & 4,2 \\
\hline Rata-rata total & 4,175 & \multicolumn{4}{|l}{} \\
\hline
\end{tabular}

\subsection{Pengujian Metode}

Untuk menguji metode fuzzy sugeno adalah dengan mencoba game level 1 sebagai perwakilan untuk level 2 dan 3 dengan cara mencoba segala kemungkinan range dari variabel time dan point setiap levelnya berdasarkan rule yang telah dibuat. Gambar 8 sampai 16 merupakan pengujian rule 1 sampai rule 9.

- Rule 1: IF time_little AND point_little THEN score_bad

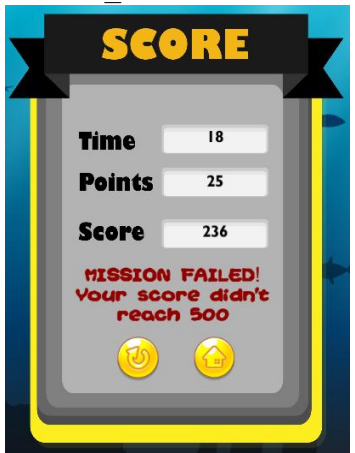

Time $=18$

$\rightarrow$ time little

Points $=25$

$\rightarrow$ point little

Score $=236$

$\rightarrow$ score_bad

Gambar 8. Rule 1

- Rule 2 : IF time_little AND point_med THEN score bad

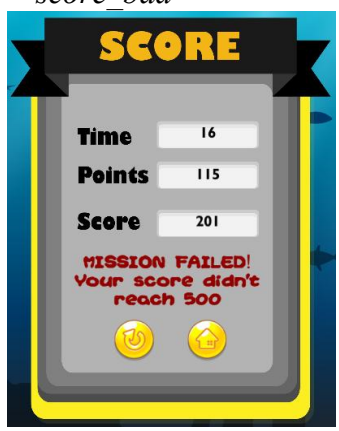

Time $=16$

$\rightarrow$ time little

Points $=115$

$\rightarrow$ point_med

Score $=201$

$\rightarrow$ score_bad

Gambar 9. Rule 2

- Rule 3 : IF time_little AND point_much THEN score good

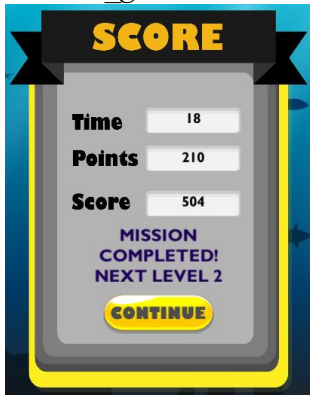

Time $=18$

$\rightarrow$ time little

Points $=210$

$\rightarrow$ point much

Score $=\overline{5} 04$

$\rightarrow$ score_good
- Rule 4:IF time_med AND point_little THEN score bad

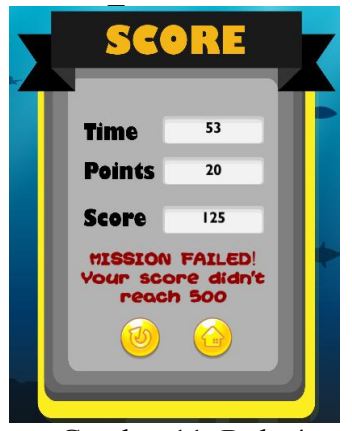

Time $=53$

$\rightarrow$ time_med

Points $=20$

$\rightarrow$ point_little

Score $=504$

$\rightarrow$ score_bad

Gambar 11. Rule 4

- Rule 5: IF time_med AND point_med THEN score_good

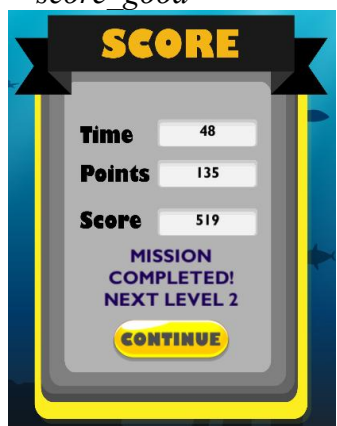

Time $=48$

$\rightarrow$ time med

Points $=135$

$\rightarrow$ point_med

Score $=519$

$\rightarrow$ score_good

Gambar 12. Rule 5

- Rule 6 : IF time med AND point much THEN score_excellent

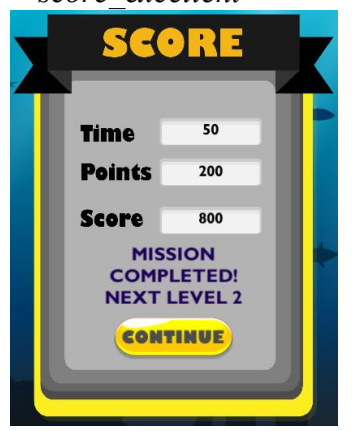

Time $=50$

$\rightarrow$ time_med

Points $=200$

$\rightarrow$ point_much

Score $=800$

$\rightarrow$ score_excellent

Gambar 13. Rule 6

- Rule 7 : IF time_much AND point_little THEN score_bad

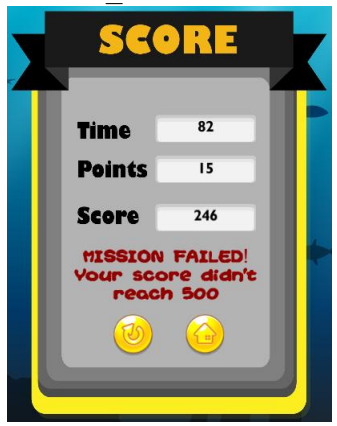

Time $=82$

$\rightarrow$ time much

Points $=15$

$\rightarrow$ point little

Score $=246$

$\rightarrow$ score_bad

Gambar 10. Rule 3

Gambar 14. Rule 7 
- Rule 8:IF time_much AND point_med THEN score_excellent

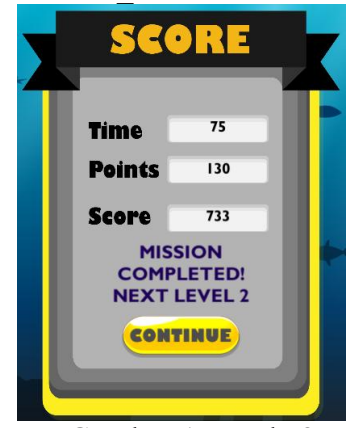

Time $=75$

$\rightarrow$ time much

Points $=130$

$\rightarrow$ point_med

Score $=733$

$\rightarrow$ score_excellent

Gambar 15. Rule 8

- Rule 9:IF time_much AND point_much THEN score_excellent

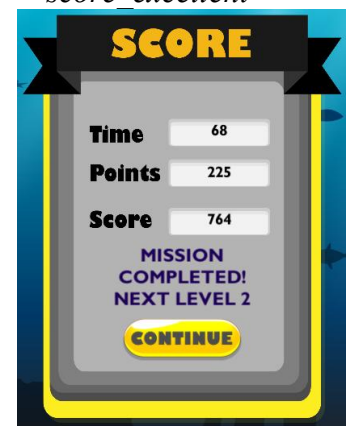

Time $=68$

$\rightarrow$ time much

Points $=225$

$\rightarrow$ point_much

Score $=764$

$\rightarrow$ score_excellent

Gambar 16. Rule 9

\subsection{Pembahasan}

Data pada Tabel 2 sampai 5 adalah hasil dari setiap pertanyaan pada kuesioner yang didapat dari pengujian kepada 30 (tigapuluh) orang mulai dari umur 9 tahun sampai umur 25 tahun. Maka dari itu, berikut adalah gambar 17 yang merupakan tampilan perbandingan rata-rata data tersebut dalam grafik.

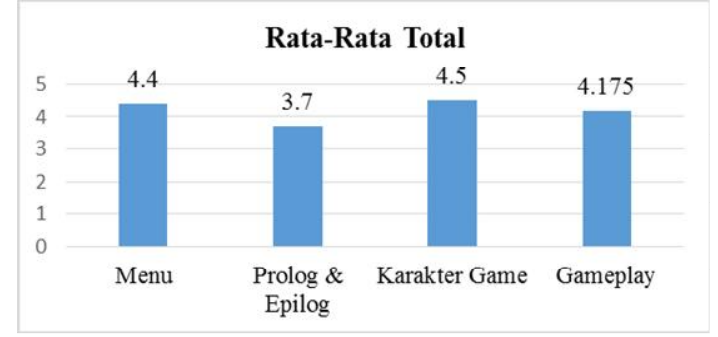

Gambar 17. Grafik rata-rata total

Kesimpulan yang didapat dari grafik yang tertera pada gambar 17 adalah kemampuan bermain user mulai dari umur 9 tahun sampai 25 tahun lebih dari cukup, mendekati baik. Penilaian pada penyampaian pengetahuan (feedback) tentang pentingnya kebersihan lingkungan laut dalam game Marine Ecosystem Hero juga baik. Tampilan menu, prolog dan epilog, serta karakter game menurut user pun juga lebih dari cukup mendekati baik.

Dari hasil kuesioner tabel 4 poin ke- 2 tentang feedback, user yang memberi nilai diatas 3 berjumlah 19 orang. Dengan demikian diperoleh hasil sebesar $63 \%$ dari 30 orang pengisi kuesioner. Sedangkan dari hasil uji coba metode yang telah dilakukan diperolah bahwa hasil implementasi metode Fuzzy Sugeno pada game sudah berjalan sesuai dengan hasil yang diinginkan.

\section{Penutup}

\subsection{Kesimpulan}

Game Marine Ecosystem Hero mampu memberikan pengetahuan mengenai pentingnya menjaga kebersihan lingkungan laut kepada generasi muda dengan hasil tingkat kepuasan user sebanyak 63\%. Perhitungan score pada game Marine Ecosystem Hero dengan menggunakan metode Fuzzy Sugeno berdasarkan variabel time dan point telah berjalan dengan baik. Menggunakan Fuzzy Sugeno pada game Marine Ecosystem Hero dapat memberikan nilai score yang awalnya hanya pernyataan yang samar menjadi nilai baru untuk menentukan kenaikan level dengan tepat.

\subsection{Saran}

Untuk penelitian lebih lanjut Game Marine Ecosystem Hero disarankan untuk mengembangkan dari berbagai sisi, khusunya dari sisi penyampaian pengetahuan. Penyampaian pengetahuan pada prolog dan epilog dapat dikembangkan lagi melalui animasi atau effect pada game. Dari sisi tingkat kesulitan pada game, setiap levelnya dapat dikembangkan dengan menambahkan perilaku musuh menggunakan kecerdasan buatan. Selain itu dari sisi desain visual dari ekosistem laut perlu dilengkapi objek-objek yang dapat memberikan ilustrasi keadaan sebenarnya.

\section{Daftar Pustaka:}

Supratna, Jatna. 2008. Melestarikan Alam Indonesia. Jakarta: Yayasan Obor Indonesia.

Wolf, Mark J.P. 2012. Encyclopedia of Video Games: M-Z. California: ABC-Clio.

Naba, Agus. 2009. Belajar Cepat Fuzzy Logic Menggunakan MATLAB, Yogyakarta: Penerbit Andi. 